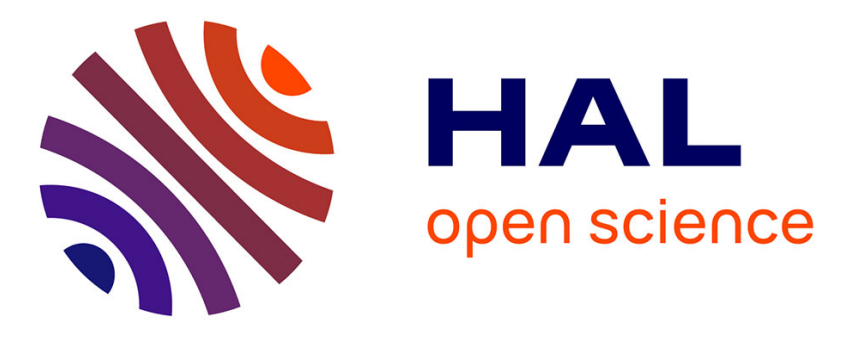

\title{
Understanding nanoscale effects in oxide/metal heteroepitaxy
}

Gregory Cabailh, Jacek Goniakowski, Claudine Noguera, Jacques Jupille, Rémi Lazzari, Jingfeng Li, Pierre Lagarde, Nicolas Trcera

\section{To cite this version:}

Gregory Cabailh, Jacek Goniakowski, Claudine Noguera, Jacques Jupille, Rémi Lazzari, et al.. Understanding nanoscale effects in oxide/metal heteroepitaxy. Physical Review Materials, 2019, 3 (4), 10.1103/PhysRevMaterials.3.046001 . hal-02127685

\section{HAL Id: hal-02127685 \\ https://hal.science/hal-02127685}

Submitted on 29 Jan 2020

HAL is a multi-disciplinary open access archive for the deposit and dissemination of scientific research documents, whether they are published or not. The documents may come from teaching and research institutions in France or abroad, or from public or private research centers.
L'archive ouverte pluridisciplinaire HAL, est destinée au dépôt et à la diffusion de documents scientifiques de niveau recherche, publiés ou non, émanant des établissements d'enseignement et de recherche français ou étrangers, des laboratoires publics ou privés. 


\title{
Understanding nanoscale effects in oxide/metal heteroepitaxy
}

\author{
Gregory Cabailh ${ }^{1 *}$, Jacek Goniakowski ${ }^{1}$, Claudine Noguera ${ }^{1}$, Jacques Jupille ${ }^{1}$, Rémi Lazzari ${ }^{1}$, Jingfeng Li $^{1}$, \\ Pierre Lagarde ${ }^{2}$, Nicolas Trcera ${ }^{2}$
}

${ }^{1}$ CNRS, Sorbonne Université, Institut des NanoSciences de Paris, UMR 7588, 4 Place Jussieu, F-75005 Paris, France ${ }^{2}$ Synchrotron SOLEIL, L'Orme des Merisiers, St-Aubin, BP48, F-91192 Gif sur Yvette, France

PACS numbers : 61.46.-w, 68.55.-a, 71.15.Mb, 78.70.Dm

The growth mode of strained epitaxial films relies on the interaction strength, the lattice matching and the mechanical response of the system. The present work focuses on the basic physics of supported nano-islands by examining the characteristics of $\mathrm{MgO} / \mathrm{Ag}(100)$ taken as a case study. The combination of experiments and simulations highlights the existence of a small size regime in which, despite the largest adhesion and the smallest mismatch, the islands are the least distorted by the substrate. We assign this unexpected behavior to the enhanced island stiffness which makes the cost of elastic distortion prohibitive compared to the associated gain of $\mathrm{MgO}-\mathrm{Ag}$ interaction energy. The analysis provides a general framework to predict and/or understand nanoscale effects on interfacial pseudomorphism. These are likely to hold whatever the nature of the deposit and substrate under consideration. It may have far reaching consequences on many properties of supported nano-objects.

\section{INTRODUCTION}

The growing number of applications of supported thin films and nanoclusters that rely on their crystallographic quality encourages scrupulous control of the epitaxy and interface structure during growth processes. Controlled crystallography is needed for optimum performances of transparent oxide semiconductors ${ }^{1,2}$, tunable ferroelectric domain structures ${ }^{3}$, heterogeneous catalysis ${ }^{4}$, optoelectronic, acousto-optical and piezoelectric devices ${ }^{5,6}$. In the usual representation of interfaces, the lattices of both supported objects and supports are strained tending to match one another ${ }^{7-9}$. Supported systems have been modeled on the basis of the "natural misfit" that stems from bulk lattice misfits ${ }^{10,11}$. The failure of those models at the very beginning of the growth ${ }^{10-12}$ led to the concept of "mesoscopic misfit" that rationalizes a significant size dependence of stress and strain [10 and refs. therein]. However, in line with the use of the continuum elastic theory for supported thin films ${ }^{13-15}$, the values of the elastic constants are often assumed size independent. The archetypal mechanical properties of nanowires, on which a great attention was focused for applications to microelectromechanical systems (MEMS), question this approximation. In wires less than a few tens of nanometers in diameter, the larger surface to volume ratio results in strongly size-dependent elastic parameters ${ }^{16-21}$. The key question is whether such dependence can be evidenced in supported nano-objects and whether it plays a role in heteroepitaxy.

$\mathrm{MgO}$ thin films are of particular interest in this context, since high crystalline quality is obtained when governed by cube-on-cube epitaxy. They are quite successfully used in magnetic tunnel junctions as crystalline barriers which, due to a highly spin-dependent evanescent decay of metallic wave functions, give rise to much higher tunnel performance than amorphous films ${ }^{22-28}$. On $\mathrm{Ag}(100)$, the $\mathrm{MgO}$ film grows in the form of islands which progressively cover the surface ${ }^{29-33} . \mathrm{MgO}(100)$ films are shown by RHEED to be pseudomorphic at the onset of their growth on $\operatorname{Ag}(100)^{34}$ and $\mathrm{Fe}(100)^{22,35}$, with $\mathrm{Ag}(001)[100] / / \mathrm{MgO}(001)[100]$ and $\mathrm{Fe}(001)[110] / / \mathrm{MgO}(001)[100]$ epitaxial relationships, respectively. In tetragonal distortions that were observed in pseudomorphically strained $3 \mathrm{ML}$ thick $\mathrm{MgO}$ films on 
$\operatorname{Ag}(100)^{36,37}$, independent measurements of the in-plane and out-of-plane lattice parameters were shown to agree with values relying on $\mathrm{MgO}$ bulk elastic constants ${ }^{36}$. In a way similar to oxides with a rock-salt structure such as $\mathrm{NiO}, \mathrm{CoO}$ and $\mathrm{MnO}^{38}$, epitaxial $\mathrm{MgO}(100)$ thin films appear as a model that apparently fulfills the prediction by Frank and van der Merwe that a pseudomorphic first layer is a prerequisite for the growth of an epitaxial 2D film ${ }^{38-40}$. However, this consensual description seems to be at odds with the prediction of a Mg-Mg distance of $2.83 \AA$ in an infinite self-supported $\mathrm{MgO}$ monolayer ${ }^{41}$. The contraction by $5 \%$ with respect to bulk $\mathrm{MgO}$ ( $2 \%$ with respect to the $\mathrm{Ag}$ lattice) casts doubt on the way in which stress and strain are driven in the supported $\mathrm{MgO}$ adlayer, insofar as the amplitude and even the sign of the exerted forces are ill-defined.

In the present paper, we show that, contrary to most assumptions made in the past, the smallest epitaxial nano-objects are less apt to adapt their structure to the support lattice to the extent in which, for particles smaller than a certain size, the internal stress outweighs the interaction with the substrate. The originality of the present work is to highlight the existence of such a small-size regime which is due to the concomitant effect of size-dependent misfit and nanoparticle stiffness. To this end, the much investigated $\mathrm{MgO} / \mathrm{Ag}(100)$ system ${ }^{29-38,41-43}$ is revisited by combining Extended X-ray Absorption Fine Structure (EXAFS) and multi-scale atomistic simulations of MgO islands. The EXAFS technique, previously quite successful to study extremely small objects unaccessible to diffraction analysis ${ }^{44}$, has been used at the $\mathrm{Mg}$ $\mathrm{K}$-edge to determine the in-plane and out-of-plane interatomic distances in $\mathrm{MgO} / \mathrm{Ag}(100)$ films grown in ultra-high vacuum conditions, for coverages ranging from the submonolayer to 10 monolayers equivalent. Numerical atomistic simulations have been performed on model unsupported and Ag-supported square $\mathrm{MgO}$ islands of various sizes and thicknesses, which are the commonly observed building blocks of growing $\mathrm{MgO}$ films ${ }^{29-31,32,37}$. The use of an original quantum method enabled the examination of the structural and energetic properties of realistic size islands.

\section{EXPERIMENTAL AND THEORETICAL METHODS}

\section{A Experimental methods}

Experiments have been performed on the Lucia beamline at the synchrotron SOLEIL (France) in an ultra-high vacuum apparatus involving a preparation chamber and a main chamber where x-ray absorption spectroscopy (XAS), low energy electron diffraction (LEED) and Auger electron spectroscopy (AES) could be operated (base pressure a few $10^{-8} \mathrm{~Pa}$ ). Scanning tunneling microscopy (STM) was performed at the Institut des Nanosciences de Paris on a variable temperature Omicron STM. For all experiments, the $\operatorname{Ag}(100)$ single crystal surface was cleaned by $\mathrm{Ar}^{+}$sputtering and then annealed at about $750 \mathrm{~K}$. Its quality was controlled by LEED and AES. MgO films were grown in the preparation chamber by evaporation of $\mathrm{Mg}$ at a rate of $0.1 \mathrm{~nm} \cdot \mathrm{min}^{-1}$ from a Knudsen cell in the presence of an oxygen partial pressure of 1 to $3 \times 10^{-4} \mathrm{~Pa}$, in conditions which ensure the stoichiometry of the oxide, a crucial precaution. The Ag sample was held at $460 \mathrm{~K}$ during growth. The average thickness of $\mathrm{MgO}$ was determined by combining measurements by quartz microbalance and jump heights at the $\mathrm{Mg} \mathrm{K}$-edge. It is given in monolayer equivalent ( 1 monolayer (ML) being defined as $1.13 \times 10^{15} \mathrm{MgO}$ units per $\mathrm{cm}^{2}$ ). The beamline was equipped with a Multilayer Grating Monochromator (MGM) and the absorption coefficient was obtained through the total electron yield (TEY) acquisition mode. An EXAFS analysis of all spectra within exactly the same protocol allowed to follow the shift of the Mg-Mg interatomic distance in the imaginary part of the Fourier Transform (FT). More details are given in Supplemental Material ${ }^{45}$.

\section{B Theoretical methods}

Atomistic simulations rely on a semi-empirical approach PHFAST (Paris Hartree Fock Atomistic 
Simulation Tool) ${ }^{41}$. It is based on a restricted Hartree-Fock variational method, in the Born-Oppenheimer approximation, in which the ground-state many-body electronic wave function is taken as a Slater determinant built from one-electron wave functions expanded on an orthogonal atomic orbital minimal basis set. Solving the Fock equations in a self-consistent manner with respect to the density matrix gives the electronic energy, as a function of the instantaneous position of the ions, to which a first-neighbor repulsion term is added. Its dependence upon the interatomic distances is driven by exponents which depend upon the type of ion pair under consideration. All parameters involved in the method are fitted to $a b$ initio results on molecules, small clusters, monolayers and bulk $\mathrm{MgO}$. In order to transform the typical $\mathrm{N}^{3}$ scaling into a linear one, a "divide and conquer" strategy is applied. For the present $\mathrm{MgO} / \mathrm{Ag}$ system, it allows to treat in a self-consistent quantum way and with full geometry optimization $\mathrm{MgO}$ islands up to c.a. $10^{5}$ atoms. A potential energy surface (PES) is used to account for the weak interaction between $\mathrm{MgO}$ and the Ag substrate. More details are given in Supplemental Material SI.2.1 ${ }^{45}$, where it is also shown that despite the PES approximation, the local distortions in $\mathrm{MgO}$ islands calculated with either PHFAST or ab initio coincide satisfactorily (SI.2.2).

\section{RESULTS}

At the onset of the $\mathrm{MgO}$ film growth, the average in-plane $\mathrm{a}_{\mathrm{MgO}-\mathrm{in}} \mathrm{Mg}-\mathrm{Mg}$ distance determined by EXAFS, is highly contracted ( $2.82 \AA$ at $\sim 0.25 \mathrm{ML}$, not only with respect to that of the bulk oxide ( $\mathrm{a}_{\text {Mgo-bulk }}$ $=2.98 \AA)$ but even relative to the Ag-Ag distance $\left(\mathrm{a}_{\mathrm{Ag}-\mathrm{bulk}}=2.89 \AA\right)$ (Fig. 1a). Upon increasing the coverage, $a_{\text {Mgo-in }}$ increases rapidly while the film is still in the form of isolated islands as seen in Scanning Tunneling Microscopy (STM) ${ }^{29-33}$ (Figs. 1d,e); it then levels off for coverages ranging between 1 and 5 $\mathrm{ML}$, at values that are intermediate between $\mathrm{a}_{\mathrm{Ag} \text {-bulk }}$ and $\mathrm{a}_{\mathrm{MgO} \text {-bulk. }}$ EXAFS spectra (Fig. $1 \mathrm{~b}$ ) and imaginary parts of the Fourier transform (Fig. 1c) related to two particular deposits clearly evidence the strong contractions of $\mathrm{a}_{\mathrm{MgO}-\text { in }}$ relative to $\mathrm{a}_{\mathrm{MgO}-\text { bulk. }}$. Beyond $5 \mathrm{ML}, \mathrm{a}_{\mathrm{MgO}-\text { in }}$ progressively tends toward $\mathrm{a}_{\mathrm{MgO} \text {-bulk }}$ (Fig. 1a). Those in-plane observations do not match the current view of a pseudomorphic growth of $\mathrm{MgO} / \mathrm{Ag}(100)$ films up to $3 \mathrm{ML}^{36,37}$. In addition, the observed tetragonal distortion (Fig. 1a), in which the out-of-plane $\mathrm{Mg}-\mathrm{Mg}$ distance $\left(\mathrm{a}_{\mathrm{MgO}-\text { out }}\right)$ is lower than $\mathrm{a}_{\mathrm{MgO} \text {-bulk }}$ (Fig.1a), runs counter the suggestion of a compensation with reference to the $\mathrm{MgO}$ bulk geometry ${ }^{36,37}$. Therefore, the EXAFS data apparently contradict the commonly accepted picture of pseudomorphic $\mathrm{MgO}(100) / \mathrm{Ag}(100)$ thin films. Another important point is the island structure and thickness. For $\mathrm{MgO}$ coverages larger than $1 \mathrm{ML}$, despite the amplitude changes due to reduced coordination numbers, profiles of EXAFS (Fig. 1b) and Fourier Transforms (Fig. 1c) are close to those observed for the bulk oxide. They are indicative of the formation of multilayered islands in which the overall structure of $\mathrm{MgO}$ is preserved (Fig. SI.1), in agreement with suggestions made by other groups ${ }^{31-34,42}$. The observation of out-of-plane distances (Fig. 1a) reveals that multilayers start to form at coverages as low as $0.5 \mathrm{ML}$. The point is supported by Finite-Difference Method Near-Edge Spectra (FDMNES) calculations of X-ray Absorption Near Edge Structure (XANES) ${ }^{46}$ (Fig. SI.2 in the Supplemental Material ${ }^{45}$ ) that were applied to model clusters made of a slab of two silver layers (16 atoms) supporting a slab of either one, two or three $\mathrm{MgO}$ planes separated by $2.7 \AA$ (see discussion below). The $\mathrm{Mg}-\mathrm{Mg}$ interatomic distances in the oxide lattice were contracted to match the Ag$\mathrm{Ag}$ distance in the $\mathrm{Ag}(100)$ surface, i.e. $2.89 \AA$. The model involving a unique $\mathrm{MgO}$ layer does not fit the data at all. In contrast, models associated to 2- and 3-layers $\mathrm{MgO}$ films quantitatively reproduce the XANES spectra (Fig. SI.2). 

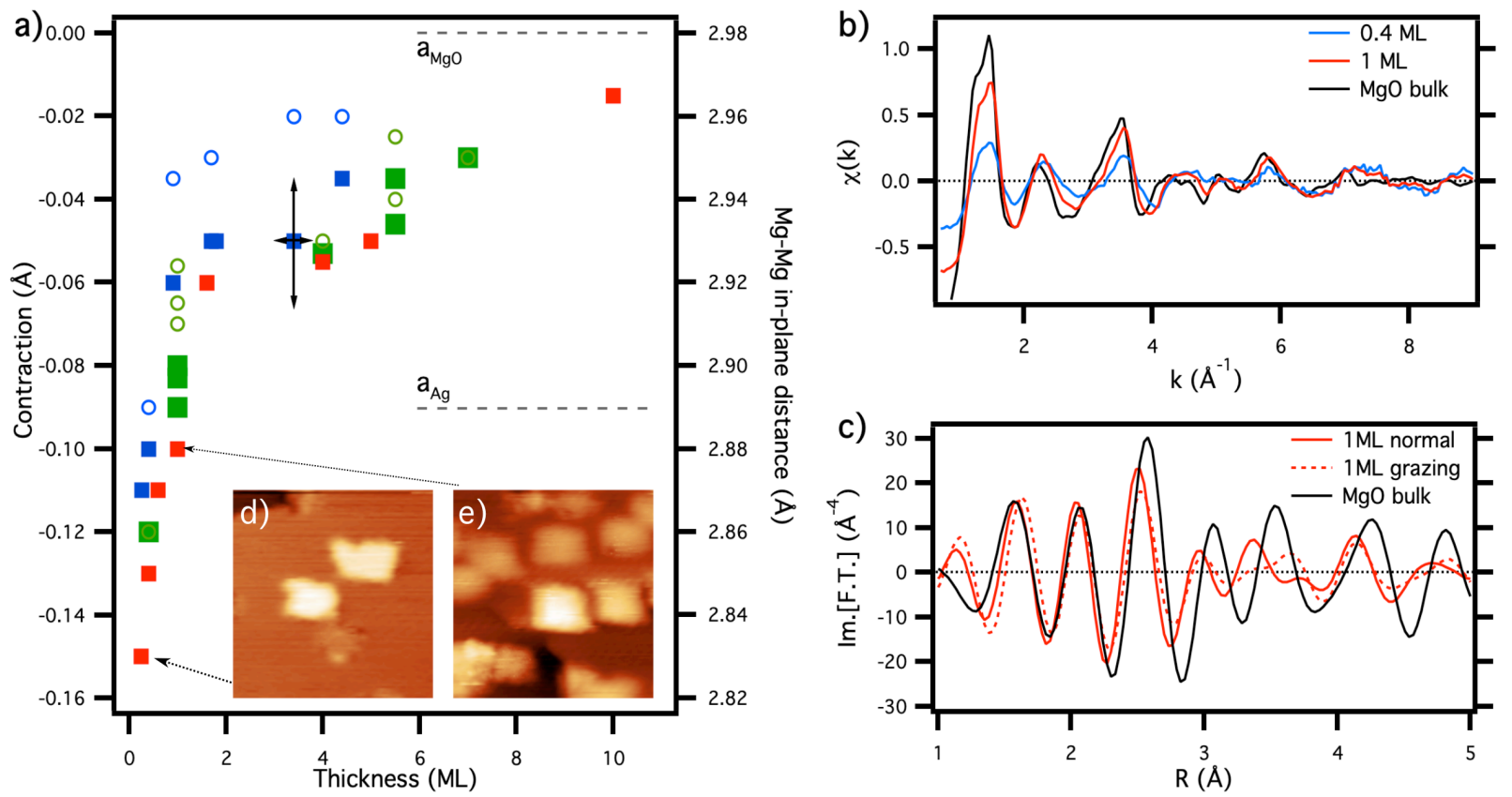

Figure 1. XAS analysis of $\mathrm{Mg}(100) / \mathrm{Ag}(100)$ films: (a) Contraction of the $\mathrm{Mg}-\mathrm{Mg}$ interatomic distance in $\mathrm{MgO}(100) / \mathrm{Ag}(100)$ films with respect to the bulk $\mathrm{MgO}$ value (2.98 $\AA$ ), as a function of the average $\mathrm{MgO}$ film thickness. The $\mathrm{MgO}$ lattice parameter is represented on the right scale and the contraction with respect to the bulk value on the left. In-plane distances (full squares, the different colors correspond to three different experimental campaigns) and out-of-plane distances (empty circles) are given. The bulk Ag- $\mathrm{Ag}(2.89 \AA)$ and $\mathrm{Mg}-\mathrm{Mg}(2.98 \AA$ in $\mathrm{MgO})$ are indicated by horizontal dashed lines; typical error bars are given by the black arrows in the figure; (b) Normal incidence $\chi(\mathrm{k})$ raw EXAFS data for MgO bulk (black), $1 \mathrm{ML}$ (red) and $0.4 \mathrm{ML}$ (blue) deposits, one monolayer being defined as $1.13 \times 10^{15} \mathrm{MgO}$ units per $\mathrm{cm}^{2}$; c) Imaginary parts of the Fourier transform (F.T.) of $\mathrm{k}^{3} \chi(\mathrm{k})$ : bulk $\mathrm{MgO}$ (black), normal (continuous red line) and grazing (dotted red line) of a $1 \mathrm{ML}$ deposit evidencing a shift of the Mg-Mg distance and a shift between normal and grazing incidences; (d) $30 \times 30 \mathrm{~nm}^{2} \mathrm{STM}$ image of a $0.4 \mathrm{ML} \mathrm{MgO}$ deposit, tunneling current $0.3 \mathrm{nA}$, bias $3.3 \mathrm{~V}$; (e) $38 \times 38 \mathrm{~nm}^{2} \mathrm{STM}$ image, $1.1 \mathrm{ML} \mathrm{MgO}, 0.1 \mathrm{nA}, 3.2 \mathrm{~V}$.

The striking contrast of the above data (Fig. 1) with the commonly accepted picture concerning the sign and amplitude of the $\mathrm{MgO} / \mathrm{Ag}(100)$ strain called for numerical simulations. The PHFAST code has been used to simulate $\mathrm{Ag}$-supported square $\mathrm{MgO}$ islands with [100]-oriented edges as a function of increasing thickness $\mathrm{H}$ from one to six layers and lateral sizes $\mathrm{L}$ up to $25 \mathrm{~nm}$, consistent with the experimentally observed $\mathrm{MgO} / \mathrm{Ag}$ islands (Fig. 1a and Refs. 29-33). The variations of the calculated inplane and out-of-plane average $\mathrm{Mg}-\mathrm{Mg}$ distances as a function of island size are displayed in Fig. 2a and $2 b$, respectively. The dimensions of the simulated islands are below the onset of appearance of interfacial dislocations in the system. Indeed, bulk values for the lattice mismatch between $\mathrm{MgO}$ and $\mathrm{Ag}$ allow to predict an onset value of the order of $10 \mathrm{~nm}$. However, the contraction of the $\mathrm{MgO}$ lattice parameter in small unsupported islands reduces the misfit (See Section IV, Discussion), which substantially increases the period of the dislocation network. Moreover, the island in-plane lattice parameters are strained by the interaction with the substrate in a way which extends the size of the island regions that are in registry with 
the substrate (Figure 2a) and thus additionally delays the onset of dislocation formation ${ }^{41}$. It is important to note that the experimental values of the $\mathrm{MgO}$ coverage are given in equivalent monolayers (ML, see Section II.a, Experimental methods), which does not presume the actual thickness of the MgO islands, while the thickness of the simulated islands or films is instead defined as a number $(\mathrm{H})$ of atomic layers.

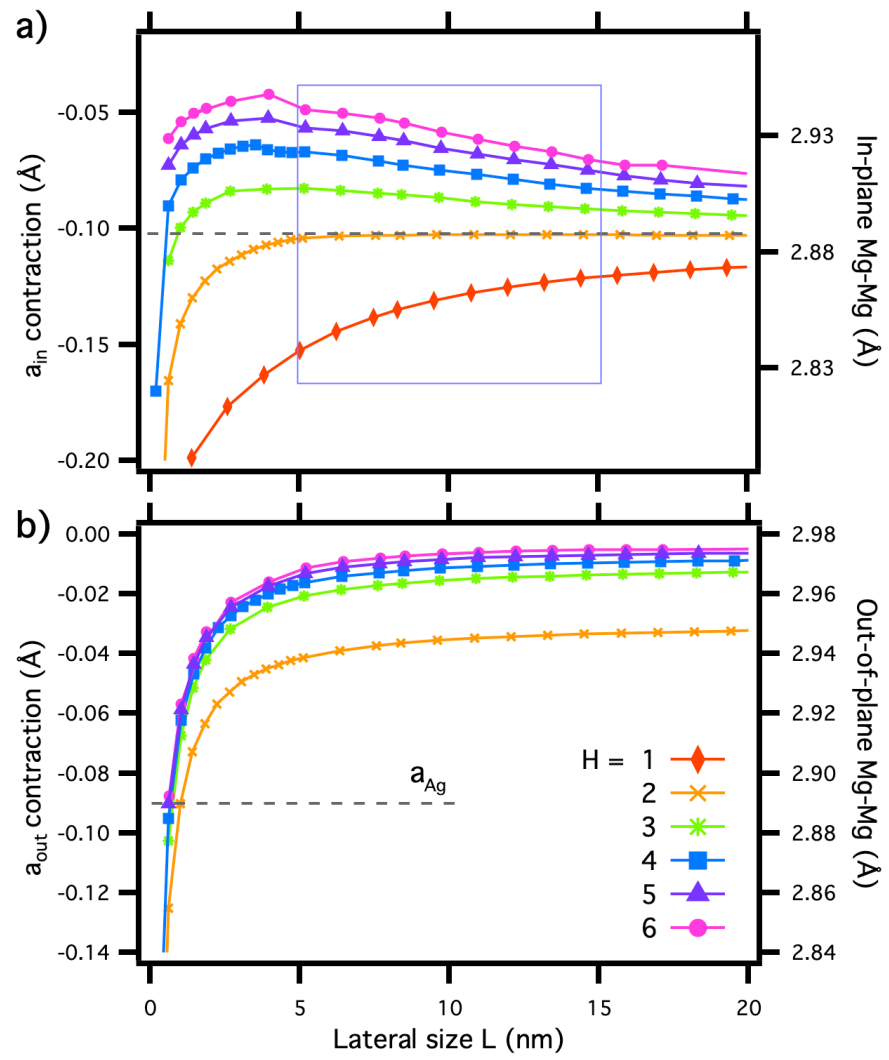

Figure 2. Numerical simulations of silver-supported square $\mathrm{MgO}$ islands. Evolution of the average contraction of the $\mathrm{Mg}-\mathrm{Mg}$ interatomic distance with respect to bulk $\mathrm{MgO}$, as a function of the island lateral size $\mathrm{L}$ and thickness $\mathrm{H}$, for islands one to six layers thick: (a) in-plane lattice parameter contraction; (b) out-of-plane parameter contraction. The value of the bulk Ag-Ag distance $\mathrm{a}_{\mathrm{Ag}}$ is indicated by horizontal dashed lines. The $5-15 \mathrm{~nm}$ size range which corresponds to the experimental (0.2-1 ML) coverage (see text) is indicated by the blue rectangle.

In simulated islands, at the smallest sizes, both in- and out-of-plane average parameters of all considered islands are strongly contracted by more than $0.15 \AA$ with respect to bulk MgO (Fig. 2). For film thicknesses $\mathrm{H}=1$ or $2, \mathrm{a}_{\mathrm{MgO}-\text { in }}$, which is always smaller than $\mathrm{a}_{\mathrm{Ag}}$, increases monotonically as a function of the island size. The 2-layers $\mathrm{MgO}$ film almost perfectly matches the silver substrate $\left(\mathrm{a}_{\mathrm{MgO}-\mathrm{in}} \sim \mathrm{a}_{\mathrm{Ag}}\right)$ for $\mathrm{L}$ $>5 \mathrm{~nm}$ (Fig. 2a). Conversely, in thicker films $(\mathrm{H}=3$ to 6$), \mathrm{a}_{\mathrm{MgO}-\text { in }}$ is non-monotonic with respect to the island size L. It shows a minimal contraction at $\mathrm{L} \sim 3-4 \mathrm{~nm}$, prior to tend progressively towards the substrate parameter $\mathrm{a}_{\mathrm{Ag}}$ when $\mathrm{L}$ increases (Fig. 2a).

Moving to the comparison between experiments and simulations, the calculated evolutions of $\mathrm{a}_{\mathrm{MgO}-\mathrm{in}}$ and $\mathrm{a}_{\mathrm{MgO}-\text { out }}$ (Fig. 2) are apparently in striking agreement with measurements (Fig. 1a). The misfit between the $\mathrm{MgO}$ and $\mathrm{Ag}$ lattices changes sign when the $\mathrm{MgO}$ coverage decreases. The highest calculated 
contraction of $0.2 \AA$ of $\mathrm{a}_{\mathrm{MgO}-\text { in }}$ meets the observation. The $\mathrm{MgO}$ lattice is found to be slightly tetragonally distorted, with $\mathrm{a}_{\mathrm{MgO}-\mathrm{in}}<\mathrm{a}_{\mathrm{MgO}-\text { out }}$, but at large coverage (Fig. 1a) or size (Fig. 2), both parameters lie between $\mathrm{a}_{\mathrm{Ag}}$ and $\mathrm{a}_{\mathrm{MgO}-\text { bulk. }}$. However, deeper analysis going beyond the overall resemblance between Fig. 1a and Fig. 2 requires a link between the measured $\mathrm{MgO}$ coverage (ML, Fig. 1a) and the calculated size/thickness (L/ $\mathrm{H}$ ) of the individual $\mathrm{MgO}$ islands (Fig. 2). EXAFS cannot distinguish between an inhomogeneous strain in nanostructures with a sharp size distribution (Fig. 3) and a scattering of island sizes. This issue can be solved by observing that for coverages ranging between 0.25 and $1 \mathrm{ML}, \mathrm{MgO}$ films involve islands of about 5 to $15 \mathrm{~nm}$ (Fig. 1d,e and Refs. 30,33). In such a size range, Fig. 2a makes it clear that, at constant height $\mathrm{H}, \mathrm{a}_{\mathrm{MgO}-\text { in }}$ is hardly affected by the lateral size $\mathrm{L}$ of the islands. Therefore, the increase of $\mathrm{a}_{\mathrm{MgO}-\text { in }}$ in the $0.25-1$ ML coverage range (Fig. 1a) cannot be rationalized by changes of $a_{\text {Mgo-in }}$ as a function of the island size at a given height $\mathrm{H}$. It has instead to be assigned to a progressive island thickening, from the dominant initial 1-layer thick $(\mathrm{H}=1) \mathrm{MgO}$ film $\left(\mathrm{a}_{\mathrm{MgO}-\text { in }}<\mathrm{a}_{\mathrm{Ag}}\right)$, up to 3 to 4-layers thick $(\mathrm{H}=3,4) \mathrm{MgO}$ films $\left(\mathrm{a}_{\mathrm{MgO}-\text { in }}>\mathrm{a}_{\mathrm{Ag}}\right.$ ). As the $\mathrm{MgO}$ coverage increases from 1 to $5 \mathrm{ML}$, islands progressively cover the surface and gradually thicken ${ }^{30,32,33}$. The experimentally observed plateau of $\mathrm{a}_{\mathrm{MgO}-\text {-in }}$ and $\mathrm{a}_{\mathrm{MgO} \text {-out }}$ in this coverage range (Fig. 1a) agrees with the structural characteristics of the simulated 4 to 6-layers thick $\mathrm{MgO}$ islands (Fig. 2). Indeed, the measured contractions of $\mathrm{a}_{\mathrm{MgO}-\mathrm{in}}(0.03-0.06 \AA)$ and $\mathrm{a}_{\mathrm{MgO}-\text { out }}(0.02-0.05 \AA)$ (Fig. 1a) are in good agreement with the corresponding computational estimations of 0.05-0.08 $\AA$ and $0.01-0.03 \AA$, respectively (Fig. 2).

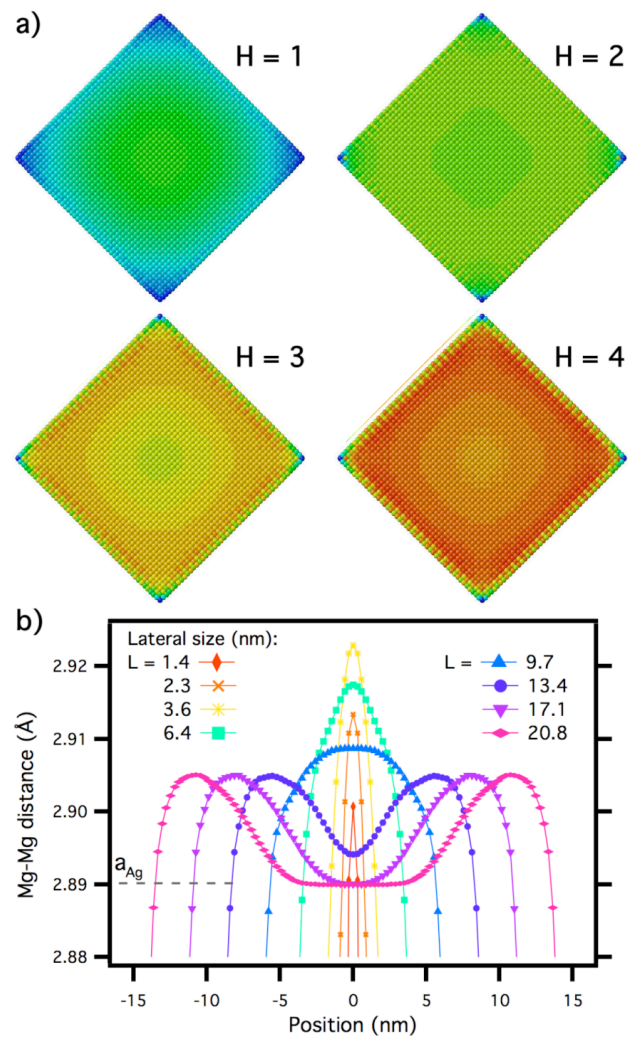

Figure 3. Simulated supported islands: (a) predicted interfacial strains throughout islands of $\sim 10$ $\mathrm{nm}$ lateral size for thickness $\mathrm{H}$ ranging from 1 to 4 layers. Contracted, pseudomorphic and expanded zones are represented in blue, green and red, respectively; (b) interfacial strain profiles along the diagonal for 4-layers thick $\mathrm{MgO} / \mathrm{Ag}(100)$ square islands of increasing lateral size (1.4 to $20.8 \mathrm{~nm}$ ). The bulk Ag-Ag distance is indicated by the dashed line. 
In the absence of coherence between the two lattices, the Mg-Ag distance will present a large scattering and its contribution to the EXAFS spectrum will be washed out by a 'static' Debye-Waller effect. On the contrary, around $1 \mathrm{ML}$, the two lattices coincide and the $\mathrm{Mg}-\mathrm{Ag}$ has a well-defined value which is then visible in EXAFS as a perturbation in the F.T. at about $3.4 \AA$ (Fig. 1c), not present in the thicker or thinner deposits. Assuming that interface $\mathrm{O}$ atoms are sitting atop surface $\mathrm{Ag}$ atoms $\mathrm{s}^{36,37}$ in an inverted image of $\mathrm{Ag} / \mathrm{MgO}(100)^{47}$ and taking a $\mathrm{Mg}-\mathrm{O}$ distance of $2.05 \AA(\mathrm{MgO} / \mathrm{Ag}$ in registry), a value of $2.7 \pm 0.15 \AA$ is obtained for the Ag-O distance. It is somewhat higher than values of $2.39 \AA^{48}$ and $2.51 \AA^{36}$ found by other groups. Our experimental finding however nicely coincides with the present vdW-DFT estimation of 2.71 $\AA$ obtained for an infinite 2-layers thick $(\mathrm{H}=2) \mathrm{MgO}(100)$ film. Taking into account the compressive strain of $\mathrm{MgO}$ deposits on $\mathrm{Ag}$, it is not surprising that this value is larger than that measured for similar Ag-O distances at the $\mathrm{Ag} / \mathrm{MgO}(100)$ interface $(2.53 \AA)^{47}$, where $\mathrm{Ag}$ is subject to a tensile strain. Consistently, this value of the distance between the $\mathrm{Ag}$ substrate and the $\mathrm{MgO}$ nanostructure is used for XANES calculations.

Focusing now on the origin of the non-monotonic behavior of $\mathrm{a}_{\mathrm{MgO}-\mathrm{in}}$, the internal lattice distortions of the islands are scrutinized at the atomic level. Fig. 3a displays the calculated interfacial strain maps of $10 \mathrm{~nm}$ wide islands of increasing thickness $(\mathrm{H}=1$ to 4$)$. It evidences highly inhomogeneous relaxation effects. Strong contractions are systematically found at edges and corners due to their small coordination number $(Z=3$ and $Z=4)$. Such an edge relaxation can strongly influence the physical properties of supported islands, as highlighted for the spin polarization and magnetic anisotropy of $\mathrm{Co} / \mathrm{Cu}(111)$ nanoclusters ${ }^{49}$. Consistent with Fig. 2a, the 1-layer thick island appears slightly contracted with respect to the $\mathrm{Ag}$ substrate. The 2-layers thick $\mathrm{MgO}$ island is almost strain-free (quasi-pseudomorphic). The thicker islands are expanded with larger interatomic distances in the border region than in the centre. To make things even more explicit, interfacial strain profiles are drawn in Fig. $3 \mathrm{~b}$ along the diagonal of 4-layers thick islands of increasing lateral sizes $(\mathrm{L}=1.4-20.8 \mathrm{~nm})$. They show two distinct behaviors. In the smallest objects $(\mathrm{L}<3.6 \mathrm{~nm}), \mathrm{Mg}-\mathrm{Mg}$ bond lengths monotonically increase from the corner to the centre, where a maximum is observed, whose value increases with $\mathrm{L}$. The situation starts changing at $\mathrm{L} \sim 3.6 \mathrm{~nm}$ where the central maximum progressively falls down and transforms into a local minimum. Beyond $\sim 14 \mathrm{~nm}$, islands display a central pseudomorphic zone the size of which increases proportionally to L. It is surrounded by a border region of constant width in which the parameter is expanded relative to $\mathrm{a}_{\mathrm{Ag}}$, prior to the steep decrease at the edges. Thus, the counter-intuitive mismatch of the average $\mathrm{MgO}$ lattice parameter in Figure 1a $\left(a_{\mathrm{MgO}-\text { in }}>\mathrm{a}_{\mathrm{Ag}}\right)$ is due to the contribution of the island border regions in which $\mathrm{a}_{\mathrm{MgO}-\text {-in }}$ is expanded with respect to $\mathrm{Ag}$ (Fig. 3b). In agreement with the above discussion, at constant lateral size, the good matching zone extends over a large part of 1-2 layers thick islands, but it progressively shrinks in thicker islands, due to the growing effect of edge contraction (Fig. 3a).

\section{DISCUSSION}

This complex strain behavior as a function of island size is to be traced back to the superposition of intrinsic and substrate-induced effects. Their respective role may be deduced from a comparison between the mean lattice parameter $\mathrm{a}_{\mathrm{MgO}-\text { in }}$ of supported and unsupported $\mathrm{MgO}$ islands shown in Fig. 4a. In unsupported islands, $\mathrm{a}_{\mathrm{MgO}-\text { in }}$ systematically displays a monotonic increase as the lateral size L grows, with asymptotic values characteristic of the infinite unsupported layers $\left(a_{\infty}=2.89,2.91,2.93\right.$ and $2.94 \AA$ for $\mathrm{H}=2,3,4$ and 5, respectively). Such behavior is consistent with the well-established decrease of the surface stress effects when the object size grows ${ }^{9,41,44}$. Unexpectedly, Fig. 4 a shows that the $\mathrm{a}_{\mathrm{MgO}-\mathrm{in}}$ of small supported islands stay very close to those of the unsupported ones, whereas the two lattice parameters depart significantly from each other for lateral sizes L larger than $\sim 3-4 \mathrm{~nm}$. 
a)

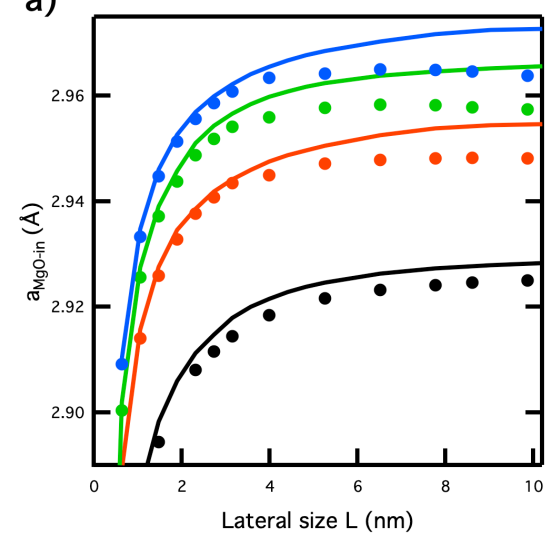

c)

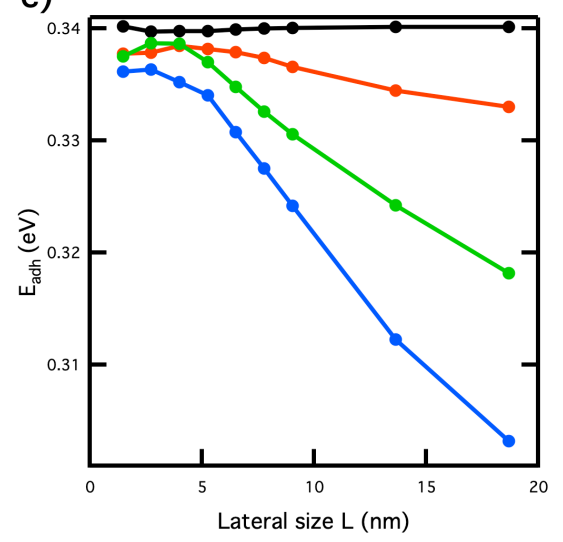

b)

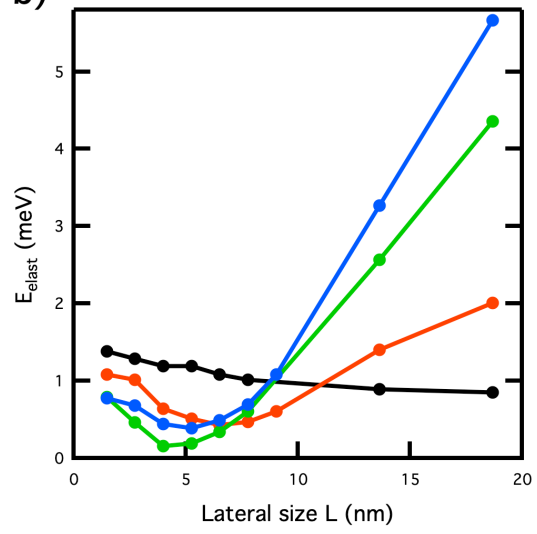

d)

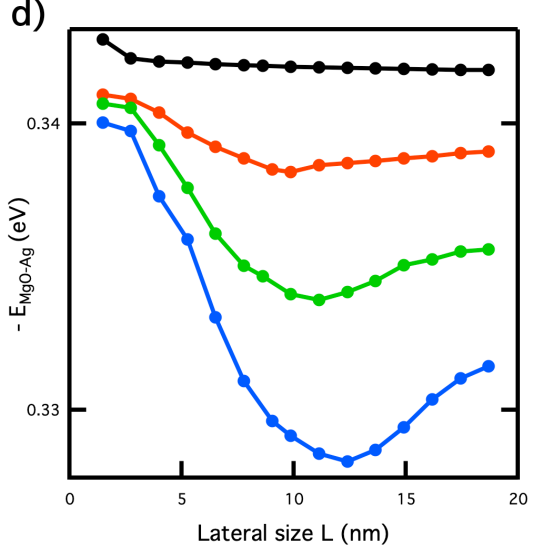

Figure 4. (a) $\mathrm{Mg}-\mathrm{Mg}$ distance $\mathrm{a}_{\mathrm{MgO}-\text {-in }}$ as a function of the island lateral size: comparison between unsupported (continuous lines) and Ag-supported (symbols) islands, (b) corresponding values of the elastic energy ( $\mathrm{meV}$ per $\mathrm{MgO}$ formula unit), (c) of the adhesion energy (eV per interfacial $\mathrm{MgO}$ unit), and (d) of the $\mathrm{MgO}-\mathrm{Ag}$ interaction (eV per interfacial $\mathrm{MgO}$ unit) (see text). Black, red, green and blue curves correspond to islands of thickness $\mathrm{H}=2,3,4$ and 5 layers, respectively.

The same change in behavior can be particularly well identified in the size dependence of the island elastic energies $E_{\text {elast }}$ (calculated as $\left(\mathrm{E}^{\mathrm{S}}{ }_{\mathrm{MgO}-\mathrm{MgO}}-\mathrm{E}^{\mathrm{US}}{ }_{\mathrm{MgO}-\mathrm{MgO}}\right) / \mathrm{N}$ where $\mathrm{E}_{\mathrm{MgO}-\mathrm{MgO}}^{\mathrm{S}}$ and $\mathrm{E}^{\mathrm{US}}{ }_{\mathrm{MgO}-\mathrm{MgO}}$ represent the intrinsic $\mathrm{MgO}$ energy of a supported and an unsupported island, respectively, and $\mathrm{N}$ the number of $\mathrm{MgO}$ formula units), shown in Fig. 4b. Nearly vanishing $E_{\text {elast }}$ found systematically at small sizes $(\mathrm{L}<3-4 \mathrm{~nm})$ prove that, despite the interaction with the substrate, islands essentially preserve their unsupported structure. In this regime, the substrate thus only plays a minor role and the island structure is intrinsically $\mathrm{MgO}$-driven. Conversely, rapid increase of $\mathrm{E}_{\text {elast }}$ at larger sizes $(\mathrm{L}>3-4 \mathrm{~nm})$ reflects a growing substrateinduced island distortion. This picture is fully consistent with the information extracted from the behavior of the adhesion energy $\mathrm{E}_{\text {adh }}$ shown in Fig. $4 \mathrm{c}$ (calculated as $\left(\mathrm{E}^{\mathrm{US}}{ }_{\mathrm{MgO}-\mathrm{MgO}}-\mathrm{E}^{\mathrm{S}}{ }_{\mathrm{MgO}-\mathrm{MgO}}-\mathrm{E}_{\mathrm{MgO}-\mathrm{Ag}}\right) / \mathrm{N}_{\text {int }}$ where $\mathrm{E}_{\mathrm{MgO}-}$ $\mathrm{Ag}$ is the interaction energy of the $\mathrm{MgO}$ island with the $\mathrm{Ag}$ support and $\mathrm{N}_{\text {int }}$ the number of interfacial $\mathrm{MgO}$ formula units). $\mathrm{E}_{\text {adh }}$ is large and nearly constant at small sizes and rapidly decreases at larger sizes (L $>3-4$ $\mathrm{nm}$ ), principally due to the contribution of $\mathrm{E}_{\text {elast. }}$ Finally, additional elements are brought by the behavior of the $\mathrm{MgO}-\mathrm{Ag}$ interaction energy $\mathrm{E}_{\mathrm{MgO}-\mathrm{Ag}} / \mathrm{N}_{\text {int }}$ (Fig. $4 \mathrm{~d}$ ). At small sizes, its progressive weakening reflects the growing incoherence between the island and the substrate lattices due to the absence of island distortion. Conversely, its strengthening in larger islands is consistent with the better interfacial matching 
associated to the growing coherent central zone. Interestingly, the transition between the two size regimes is progressive rather than abrupt. Indeed, its signature at $\mathrm{L} \sim 3-4 \mathrm{~nm}$ in Figs. $4 \mathrm{~b}$ and $4 \mathrm{c}$ correlates well with a change in behavior (from increasing to decreasing) of the central maximum in Fig. 3b, which marks the size at which substrate-induced distortions become detectable. Conversely, the turning points of the MgO-Ag interaction energy, Fig. 4d, only occur at larger island sizes ( $\mathrm{L} \sim 10-12 \mathrm{~nm}$ ), which is consistent with the progressive island distortion necessary to enhance the central coherence zone.

The very origin of the qualitative difference between the small and large size regimes is to be traced back to the competition between the elastic cost of deformation needed to match the substrate lattice and the related gain of $\mathrm{MgO}-\mathrm{Ag}$ interaction energy. Counterintuitively, our results show that at small sizes, despite the largest adhesion, the substrate-induced distortions are the smallest. This is due to the enhanced

island stiffness ${ }^{16,20,21,50,51}$, which makes the cost of elastic distortion prohibitive compared to what would be gained by MgO-Ag interaction energy (SI.2.3).

Our results can be used to explain insofar puzzling phenomena which involve non-monotonic behaviors similar to those reported here. For example, to produce defect-free $\mathrm{MgO}$ barrier in magnetic tunnel junctions, the growth of $\mathrm{MgO}$ films has been studied on $\mathrm{Fe}_{\mathrm{x}} \mathrm{V}_{1-\mathrm{x}}(100)$ surfaces $\left(\mathrm{x}=0\right.$ to $0.7 ; \mathrm{a}_{\mathrm{FeV}}=$ 2.87-2.98 $\AA$, the latter value corresponding in principle to a zero misfit compared to the bulk) ${ }^{52}$. Contrary to expectation, these films never appeared to be pseudomorphic. At the onset of the deposition, the $\mathrm{MgO}$ parameter increased above that of the FeV substrate peaked at a coverage of 2-3 ML and then, in a surprising evolution, it decreased. It finally shifted slowly toward the bulk $\mathrm{MgO}$ value ${ }^{52}$. Such nonmonotonic variation of the $\mathrm{MgO} / \mathrm{Fe}_{\mathrm{x}} \mathrm{V}_{1-\mathrm{x}}(100)$ parameter with $\mathrm{MgO}$ coverage is strongly reminiscent of the $\mathrm{MgO} / \mathrm{Ag}(100)$ behavior found in the present study (Fig. 2), associated to the existence of a small size regime. Similarly, the deposition of $\mathrm{Ag}$ clusters on a $\mathrm{MgO}(100)$ surface ${ }^{44,53}$ has evidenced silver clusters close to pseudomorphy for sizes ranging between $\sim 1$ and $2 \mathrm{~nm}$, with an Ag lattice parameter expanded by more than $3 \%$ to match the $\mathrm{MgO}(100)$ surface. However, interestingly, a small size regime was found below $\sim 1 \mathrm{~nm}$ in which the silver parameter shrank by more than $6 \%$ back to what was predicted for unsupported clusters.

\section{CONCLUSION}

To summarize, we have highlighted the structural characteristics of Ag-supported $\mathrm{MgO}$ islands, including a change of sign of the misfit between the two lattices and a non-monotonic variation of the island lattice parameter as a function of island size. More importantly, we have revealed the existence of an original small-size regime in which, owing to an effect associated to the size-dependent misfit and stiffness, the smallest nano-objects are less apt to adapt their structure to the support lattice. Against received ideas, they are able to escape the influence of the support more easily than the largest objects, despite a higher adhesion energy and a smaller lattice mismatch. The construction of such a general conceptual framework was possible thanks to a coupling between EXAFS experiments and multiscale numerical modeling. The former enabled a structural characterization in a particularly large range of sizes, including those inaccessible to standard diffraction techniques. The latter provided both realistic structural island models and precise mapping of island energetics. Our results on $\mathrm{MgO} / \mathrm{Ag}$ help to clarify the longstanding question on the nature of sub-monolayer oxide deposits at one of the most studied non-reactive oxide/metal interfaces. Moreover, the generality of the revealed microscopic mechanisms makes them relevant also for early growth stages in a much larger class of supported nano-objects, including, e.g. $\mathrm{MgO} / \mathrm{Fe}$, for which the nature of the metal/oxide interface is determinant for its magneto-resistive properties used in tunnel junctions.

\section{ACKNOWLEDGEMENTS}

We thank the team in charge with the SOLEIL machine and Damien Roy (LUCIA beamline) for his technical assistance. J.L. acknowledges support from the China Scholarship Council for his Ph.D. Grant. 
* electronic adress : gregory.cabailh@sorbonne.universite.fr

1. K. Nomura, H. Ohta, K. Ueda, T. Kamiya, M. Hirano and H. Hosono, Science 300, 1269 (2003).

2. H. Hosono, Thin Solid Films 515, 6000 (2007).

3. R. J. Xu, S. Liu, I. Grinberg, J. Karthik, A. R. Damodaran, A. M. Rappe and L. W. Martin, Nat. Mater. 14, 79 (2015).

4. C. R. Henry, Surf. Sci. Rep. 31, 231, 235 (1998).

5. Ü. Özgür, Y. I. Alivov, C. Liu, A. Teke, M. A. Reshchikov, S. Doğan, V. Avrutin, S.-J. Cho and H. A Morkoç, J. Appl. Phys. 98, 041301 (2005).

6. L. Znaidi, Mater. Sci. Eng. B 174, 18 (2010).

7. P. Müller and A. Saul, Surf. Sci. Rep. 54, 157 (2004).

8. B. R. Cuenya, Acc. Chem. Res. 46, 1682 (2013).

9. L. D. Marks and L. Peng, J. Phys.: Condens. Matter 28, 053001 (2016).

10. O. O. Brovko, D. I. Bazhanov, H. L. Meyerheim, D. Sander, V. S. Stepanyuk and J. Kirschner, Surf. Sci. Rep. 69, 159 (2014).

11. P. Müller, P. Turban, L. Lapena and S. Andrieu, Surf. Sci. 488, 52 (2001).

12. V. S. Stepanyuk, D. I. Bazhanov, A. N. Baranov, W. Hergert, P. H. Dederichs and J. Kirschner, Phys. Rev. B 62, 15398 (2000).

13. J. Tersoff and R. M. Tromp, Phys. Rev. Lett. 70, 2782 (1993).

14. B. J. Spencer and J. Tersoff,. Phys. Rev. Lett. 79, 4858 (1997).

15. A. Li, F. Liu and M. G. Lagally, Phys. Rev. Lett. 85, 1922 (2000).

16. C. Q. Chen, Y. Shi, Y. S. Zhang, J. Zhu and Y. J. Yan, Phys. Rev. Lett. 96, 075505 (2006).

17. C.-Y. Nam, P. Jaroenapibal, D. Tham and D. E. Luzzi, Nano Lett. 6, 153 (2006).

18. R. Agrawal, B. Peng, E. E. Gdoutos and H. D. Espinosa, Nano Lett. 8, 3668 (2008).

19. R. A. Bernal, R. Agrawal, B. Peng, K. A. Bertness, N. A. Sanford, A. V. Davydov and H. D. Espinosa, Nano Lett. 11, 548 (2011).

20. R.J. Wang, C.Y. Wang and Y.T. Feng, IJMS 130, 267 (2017).

21. B. A. M. Elsner, S. Müller, S. Bargmann and J. Weissmüller, Acta Mater. 124, 468 (2017).

22. W. Wulfhekel, M. Klaua, D. Ullmann, F. Zavaliche, J. Kirschner, R. Urban, T. Monchesky and B. Heinrich, Appl. Phys. Lett. 78, 509 (2001).

23. W. H. Butler, X.-G. Zhang, T. C. Schulthess and J. M. MacLaren, Phys. Rev. B 63, 054416 (2001).

24. J. Mathon and A. Umerski, Phys. Rev. B 63, 220403 (2001).

25. S. S. P. Parkin, C. Kaiser, A. Panchula, P. M. Rice, B. Hughes, M. Samant and S. H. Yang, Nat. Mater. 3, 862 (2004).

26. Y. Fan, K. J. Smith, G. Lüpke, A. T. Hanbicki, R. Goswami, C. H. Li, H. B. Zhao and B. T. Jonker, Nat. Nanotechnol. 8, 438 (2013).

27. A. Kozioł-Rachwał, T. Ślęzak, M. Ślęzak, K. Matlak, E. Młyńczak, N. Spiridis, and J. Korecki, J. Appl. Phys. 115, 104301 (2014).

28. C. Bellouard, A. Duluard, E. Snoeck, Y. Lu, B. Negulescu, D. Lacour, C. Senet, S. Robert, N. Maloufi, S. Andrieu, M. Hehn and C. Tiusan, Phys. Rev. B 96, 134416 (2017).

29. J. Wollschläger, D. Erdös and K.-M. Schröder, Surf. Sci. 402-404, 272 (1998).

30. S. Schintke, S. Messerli, M. Pivetta, F. Patthey, L. Libioulle, M. Stengel, A. De Vita and W.-D. Schneider, Phys. Rev. Lett. 87, 276801 (2001).

31. S. Valeri, S. Altieri, U. del Pennino, A. di Bona, P. Luches, and A. Rota, Phys. Rev. B 65, 245410 (2002).

32. S. Baumann, I. G. Rau, S. Loth, C. P. Lutz and A. J. Heinrich, ACS Nano 8, 1739 (2014).

33. A. Ouvrard, J. Niebauer, A. Ghalgaoui, C. Barth, C. R. Henry and B. Bourguignon, J. Phys. Chem. C 115, 8034 (2011).

34. M. Kiguchi, T. Goto, K. Saiki, T. Sasaki, Y. Iwasawa and A. Koma, Surf. Sci. 512, 97(2002). 
35. M. Klaua, D. Ullmann, J. Barthel, W. Wulfhekel, J. Kirschner, R. Urban, T. L. Monchesky, A. Enders, J. F. Cochran and B. Heinrich, Phys. Rev. B 64, 134411 (2001).

36. P. Luches, S. D’Addato, S. Valeri, E. Groppo, C. Prestipino, C. Lamberti and F. Boscherini, Phys. Rev. B 69, 045412 (2004).

37. S. Valeri, S. Altieri, A. di Bona, C. Giovanardi and T. S. Moia, Thin Solid Films 400, 16 (2001).

38. T. Obermüller, N. Doudin, D. Kuhness, S. Surnev and F. P. Netzer, J. Mater. Res. 32, 3924 (2017).

39. F. C. Frank and J. H. van der Merwe, Proc. Roy. Soc. London A 198205 (1949).

40. S. C. Jain and W. Hayes, Semicond. Sci. Technol. 6, 547 (1991).

41. C. Noguera, J. Godet and J. Goniakowski, Phys. Rev. B 81, 155409 (2010).

42. T. Jaouen, S. Tricot, G. Delhaye, B. Lépine, D. Sébilleau, G. Jézéquel and P. Schieffer, Phys. Rev. Lett. 111, 027601 (2013).

43. A. M. Ferrari, S. Casassa and C. Pisani, Phys. Rev. B 71, 155404 (2005).

44. R. Lazzari, J. Goniakowski, G. Cabailh, R. Cavalotti, N. Trcera, P. Lagarde and J. Jupille, Nano Lett. 16, 2574 (2016).

45. See Supplemental Material at [URL will be inserted by publisher] for further details on the experimental methods and set-ups (first part) as well as theoretical methods and results (second part).

46. J. D. Bourke, C. T. Chantler and Y. Joly, J. Synchrotron Rad. 23, 551 (2016).

47. A. M. Flank, R. Delaunay, P. Lagarde, M. Pompa and J. Jupille, Phys. Rev. B 53, R1737 (1996).

48. C. Giovanardi, A. di Bona, T. S. Moia, S. Valeri, C. Pisani, M. Sgroi and M. Busso, Surf. Sci. 505, L209 (2002).

49. D. Sander, S.-H. Phark, M. Corbetta, J. A Fischer, H. Oka and J. Kirschner, J. Phys.: Cond. Matter 26, 394008 (2014).

50. C. T. Sun and H. Zhang, J. Appl. Phys. 93, 1212 (2003).

51. C. Lee, H. Yan, L. E. Brus, T. F. Heinz, J. Hone and S. Ryu, ACS Nano 4, 2695 (2010).

52. F. Bonell and S. Andrieu, Surf. Sci. 656, 140 (2017).

53. P. Lagarde, S. Colonna, A.-M. Flank and J. Jupille, Surf. Sci. 524, 102 (2003). 